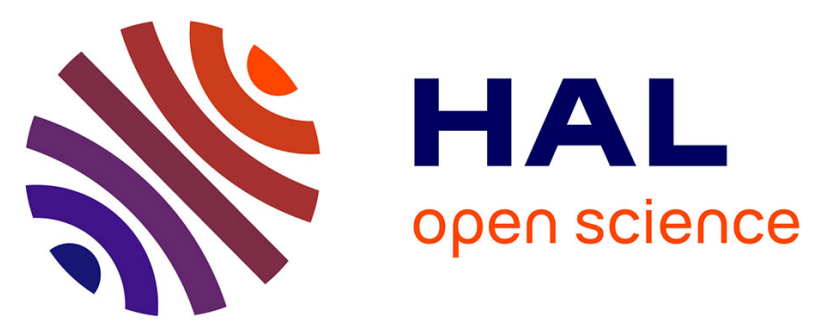

\title{
Secondary metabolites from lichen as potent inhibitors of advanced glycation end products and vasodilative agents
}

Andreas Schinkovitz, Pierre Le Pogam, Séverine Derbré, Emilie Vessieres, Patricia Blanchard, Sangeetha-Laura Thirumaran, Dimitri Bréard, Marie-Christine Aumond, Martin Zehl, Ernst Urban, et al.

\section{To cite this version:}

Andreas Schinkovitz, Pierre Le Pogam, Séverine Derbré, Emilie Vessieres, Patricia Blanchard, et al.. Secondary metabolites from lichen as potent inhibitors of advanced glycation end products and vasodilative agents. Fitoterapia, 2018, 131, pp.182-188. 10.1016/j.fitote.2018.10.015 . hal-01903310

HAL Id: hal-01903310

https://hal-univ-rennes1.archives-ouvertes.fr/hal-01903310

Submitted on 9 Nov 2018

HAL is a multi-disciplinary open access archive for the deposit and dissemination of scientific research documents, whether they are published or not. The documents may come from teaching and research institutions in France or abroad, or from public or private research centers.
L'archive ouverte pluridisciplinaire HAL, est destinée au dépôt et à la diffusion de documents scientifiques de niveau recherche, publiés ou non, émanant des établissements d'enseignement et de recherche français ou étrangers, des laboratoires publics ou privés. 
Secondary metabolites from lichen as potent inhibitors of advanced glycation end products and vasodilative agents

Andreas Schinkovitz, ${ }^{\mathrm{a}^{*}}$ Pierre Le Pogam, ${ }^{\mathrm{b}, \mathrm{c}}$ Séverine Derbré, ${ }^{\mathrm{a}}$ Emilie Vessieres, ${ }^{\mathrm{e}}$ Patricia Blanchard, ${ }^{\mathrm{a}}$ Sangeetha-Laura Thirumaran, ${ }^{\text {a,f }}$ Dimitri Breard, ${ }^{\mathrm{a}}$ Marie-Chistine Aumond, ${ }^{\mathrm{a}}$ Martin Zehl, ${ }^{\mathrm{g}}$ Ernst Urban, ${ }^{\mathrm{h}}$ Amandeep Kaur, ${ }^{\mathrm{i}}$ Nathalie Jäger, ${ }^{\mathrm{i}}$ Stefanie Hofer, ${ }^{\mathrm{a}, \mathrm{j}}$ Brigitte Kopp, ${ }^{\mathrm{i}}$ Hermann Stuppner, ${ }^{\mathrm{j}}$ Isabelle Baglin, ${ }^{\mathrm{a}}$ Denis Seraphin, ${ }^{\mathrm{a}}$ Sophie Tomasi, ${ }^{\mathrm{b}}$ Daniel Henrion, ${ }^{\mathrm{f}}$ Joël Boustie, ${ }^{\mathrm{b}}$ Pascal Richomme. ${ }^{\text {a }}$

${ }^{a}$ Université d'Angers, SONAS/SFR QUASAV, Campus du Végétal, 42 rue Georges Morel, 49070 Beaucouzé, France

bUniversité Rennes, CNRS, ISCR - UMR 6226, F-35000 Rennes, France

${ }^{c}$ BioCIS, Université Paris-Sud, CNRS, Université Paris-Saclay, 5 Rue J.-B. Clément, 92290 Châtenay-Malabry, France

'Université d'Angers, MITOVASC Institute, CarMe team, INSERM U1083, CNRS UMR6015, CARFI facility,3 rue Roger Amsler, 49100 Angers, France

${ }^{\mathrm{f}}$ Université de Caen Normandie, Centre d'Etudes et de Recherche sur le Médicament de Normandie (CERMN), 14000 Caen, France

${ }^{\mathrm{g}}$ University of Vienna, Department of Analytical Chemistry, Währinger Straße 38, 1090 Vienna, Austria

${ }^{\mathrm{h}}$ University of Vienna, Department of Pharmaceutical Chemistry, Althanstraße 14, 1090 Vienna, Austria

${ }^{\mathrm{i}}$ University of Vienna, Department of Pharmacognosy, Althanstraße 14, 1090 Vienna, Austria ${ }^{j}$ University of Innsbruck, Institute of Pharmacy/Pharmacognosy, Center for Chemistry and Biomedicine, Innrain 80 - 82/IV, 6020 Innsbruck, Austria

*Corresponding author

\section{Abstract}

Secondary metabolites from lichens are known for exhibiting various biological effects such as anti-inflammatory, antioxidant and antibacterial activities. Despite this wide range of reported biological effects, their impact on the formation of advanced glycation end products (AGEs) remains vastly unexplored. The latter are known contributors to lifestyle and age-related diseases such as Alzheimer and Parkinson. Moreover, the development of atherosclerosis and arterial stiffness is causally linked to the formation of AGEs. With this in mind, the present work evaluated the inhibitory effects of secondary lichen metabolites on the formation of pentosidinelike AGEs by using an in vitro, Maillard reaction based, fluorescence assay. Overall, thirty-seven natural and five synthetically modified compounds were tested, eighteen of which exhibiting $\mathrm{IC}_{50}$ values in the range of 0.05 to $0.70 \mathrm{mM}$, which corresponds to 2 to 32 fold of the inhibitory activity of aminoguanidine. In addition, all compounds were evaluated on their radical scavenging capacities in an DPPH assay targeting one major inhibiting mechanism of AGEs formation. Furthermore, as both AGEs' formation and hypertension are major risk factors for 
atherosclerosis, compounds that were available in sufficient amounts were also tested for their vasodilative effects. Although some of the active compounds were previously reported cytotoxic, present results highlight the interesting potential of secondary lichen metabolites as anti-AGE and vasodilative agents.

Keywords: Inhibition of Advanced Glycation End Products, Maillard reaction, Radical scavenging, Lichen metabolites, Vasodilation.

Declarations of interest: none 


\section{Introduction}

With increasing affluence, lifestyle diseases have gained significant impact on population's morbidity in industrialized countries. Particularly malnutrition and the lack of exercise substantially contribute to the spread of diabetes. Moreover, an aging population is progressively affected by neurodegenerative diseases such as Parkinson and Alzheimer.

Advanced glycation end products (AGEs) are known contributors to many of these diseases as their formation is directly linked to diabetic long term complications such as endothelial dysfunctions [1], impaired microcirculation [2], as well as $\beta$-amyloid formation in Alzheimer [3]. Moreover, AGEs were histochemically detected in the frontal cortex of Parkinson patients [4], and also found to substantially impact the development of arterial stiffness and atherosclerosis [5, 6]. For the time being no successful therapeutic intervention targeting the inhibition of AGEs formation has been developed.

Natural products (NPs) are known for exhibiting a wide range of very different pharmacological effects [7], including the inhibition AGEs formation [8-12] and consequently the limitation of endothelial damage [13]. Moreover, many promising candidates show additional antioxidant or radical scavenging activities [14], and belong to different chemical families such as polyphenols [11], terpenes, and alkaloids [9]. While plants and their anti-AGEs effects have been thoroughly studied, the impact of lichens and their secondary metabolites remains mostly unexplored [15].

Lichens are symbiotic organisms comprising filamentous fungi and photosynthetic partners such as eukaryotic algae or cyanobacteria. This unique combination yields very particular metabolites that cannot be found in the isolated partners or elsewhere in nature. Many of these compounds do exhibit notable biological activities like anti-inflammatory, antioxidant, antibacterial, and cytotoxic effects [16-19], however, very little is known about their effect on the formation of AGEs [15]. With this in mind, the present study evaluated thirty-seven secondary lichen metabolites as well as five semisynthetic derivatives of usnic acid (a major metabolite found in many lichen species) for their potential anti-AGE effects in a fluorescence-based Maillard reaction assay [20]. According to previous reports, anti-AGE, antioxidant, and radical scavenging effects are often related, so all compounds were additionally tested in an 1,1-diphenyl-2picrylhydrazyl (DPPH) assay [14, 21, 22]. Considering that both AGEs but also hypertension are known important risk factors for age- and lifestyle related diseases, some compounds, that were available in sufficient quantities, were further evaluated in a vasodilation assay.

\section{Experimental}

\subsection{Chemical and Material}

Bovine serum albumin (BSA, fraction V), potassium phosphate monobasic, potassium phosphate dibasic trihydrate, sodium azide, and aminoguanidine hydrochloride were all purchased from Sigma-Aldrich (St Quentin Fallavier, France). D-ribose was obtained from Alfa Aesar (Schiltigheim, France) and 1,1-diphenyl-2-picrylhydrazyl (DPPH), 6-hydroxy-2,5,7,8tetramethylchroman-2-carboxylic acid (Trolox $®)$ and chlorogenic acid were purchased from 
Acros Organics (Noisy-Le-Grand, France). Secondary metabolites from lichen were isolated and elucidated within preceding research projects and as being outlined in the literature [19, 23, 24]. Table S3, (supplementary material) indicates the natural source of the tested compounds. Semisynthetic modifications of usnic acid (35) conducted for obtaining compounds 38 and 42 were performed according to previously published protocols [25, 26]. Detailed information on compounds 39-41 is given in the supplementary material section.

\subsection{Advanced glycation end-products inhibition assay}

Inhibition of pentosidine-like AGEs formation was measured according to a previously published protocol [27]. In short: depending on available sample material, stock solutions (SS) were prepared in DMSO at concentrations of 10 or $30 \mathrm{mM}$ respectively. These SS were then diluted with $50 \mathrm{mM}$ phosphate buffer ( $\mathrm{pH}$ : 7.4) yielding working solutions (WS) at a concentration range of $10^{-2}$ to $10^{-5} \mathrm{~mol} / \mathrm{L}$. Ten microliter of each WS were deposited in 96 black well bottom plates (Fisher Scientific, Illkirch, France) and mixed with $90 \mu \mathrm{L}$ of a solution containing BSA $(11 \mathrm{mg} / \mathrm{L})$, D-ribose $(0.25 \mathrm{M})$, and phosphate buffer $\left(50 \mathrm{mM}, \mathrm{NaN}_{3} 0.02 \%, \mathrm{pH} 7.4\right)$. Plates were then incubated for $24 \mathrm{~h}$ at $37^{\circ} \mathrm{C}$, before being fluorometrically analyzed ( $\lambda_{\text {exc }}: 335 \mathrm{~nm}$, $\lambda_{\text {em }}: 385 \mathrm{~nm}$ ) using an Infinite M200 plate reader (Tecan, Lyon, France). Aminoguanidine (Sigma-Aldrich) was used as positive control. The formation of AGEs was calculated according the following formula ( $\mathrm{FI}=$ florescence intensity):

$$
\frac{[F I(B S A+\text { ribose }+ \text { sample })-F I(B S A+\text { sample })] \times 100}{F I(B S A+\text { ribose })-F I(B S A)}
$$

Results (table 1) are expressed as $\mathrm{IC}_{50}(\mathrm{mM})$ and fold inhibition compared to aminoguanidine (positive control). Samples exhibiting an $\mathrm{IC}_{50}$ of more than $1 \mathrm{mM}$ or less than two fold of the activity of aminoguanidine were considered inactive. Dimethyl sulfoxide served as negative control and was processed the same way as the WS.

\subsection{Radical scavenging and reductive assay $(D P P H)$}

Radical-scavenging and reductive activities of test compounds were evaluated in an DPPH assay according to a previously reported protocol with small modifications [28]. Stock solutions previously used for the AGEs assay were diluted in absolute ethanol to afford WS at 200 and 40 $\mu \mathrm{g} / \mathrm{mL}$. Due to its high reductive potential, the WS of compound 34 was lowered to 20 and 10 $\mu \mathrm{g} / \mathrm{mL}$. Next, $100 \mu \mathrm{L}$ of these WS were transferred into a 96 well plate and mixed with $25 \mu \mathrm{L}$ freshly prepared ethanolic DPPH solution $(0.25 \mathrm{mM})$ and $75 \mu \mathrm{L}$ absolute EtOH. Samples were incubated under light protection for $30 \mathrm{~min}$ at $20^{\circ} \mathrm{C}$ before being photometrically analyzed ( $\lambda_{\text {abs: }}$ : $517 \mathrm{~nm})$. Ethanol was used as negative, chlorogenic acid $(20 \mu \mathrm{g} / \mathrm{mL})$ as positive control. Reference solutions were prepared using Trolox ${ }^{\circledR}$ at concentrations of 10, 25, 50, and $75 \mu \mathrm{M}$. Results are expressed as $\mu$ mol equivalents of Trolox ${ }^{\circledR}$ per sample. Samples exhibiting activities of less than $10 \%$ of chlorogenic acid were considered inactive. 


\subsection{Vasodilation assay}

The experimental protocol is based on a previously published report with small modifications [29]. Three-month-old male Kyoto Wistar rats (obtained from the "service commun d'animalerie hospitalo- universitaire" of the University of Angers) were sacrificed by $\mathrm{CO}_{2}$ exposure. The mesentery was removed and the first order mesenteric arteries were dissected. Segments of arteries (2 mm long) were mounted on a wire myograph (DMT, Aarhus, Denmark) by two tungsten wires $(40 \mu \mathrm{m}$ in diameter) that were inserted into the lumen of the arteries and attached to a force transducer and a micrometer. The arteries were rinsed with a physiological buffer solution (PBS) at $37^{\circ} \mathrm{C}$ and $\mathrm{pH}$ 7.4. Wall tension was monitored using the AcqKnowledge software (BIOPAC Systems, Inc., Goleta, CA). After wall-tension stabilization (45 min), vessel viability was tested three times (respecting a five-minute interval) using a potassium-enriched ( 80 $\mathrm{mM}$ ) PBS solution. After $10 \mathrm{~min}$, endothelium integrity was controlled by inducing a precontraction with phenylephrine $(2 \mu \mathrm{M})$, followed by an induced relaxation using acetylcholine at the same concentration. Arterial segments were then pre-contracted with phenylephrine $(2 \mu \mathrm{M})$ and a cumulative concentration-response experiment for each compound was performed. Compounds were dissolved in DMSO yielding SS at a concentration of $20 \mathrm{mg} / \mathrm{mL}$. These SS were then diluted with PBS yielding final sample concentrations of 0.2, 0.6, 2.0, 6.0 and 20.0 $\mu \mathrm{g} / \mathrm{mL}$. Vasodilative activity is expressed as the effective dose required for obtaining $50 \%$ vasodilation $\left(\mathrm{ED}_{50}\right)$ of precontracted vessels. Dimethyl sulfoxide served as negative control and was processed the same way as sample solutions. As shown in Fig 2, DMSO by itself exhibited some vasodilative effects, however its $\mathrm{ED}_{50}$ was 4-10 fold higher than those of lichen constituents. Information showing the exact molar concentrations of all samples was added to the supplementary information section (Table S1, S2).

\section{Results and discussion}

\subsection{Inhibition of AGEs formation and radical scavenging activities}

As discussed earlier secondary lichen metabolites are well known for exhibiting a large variety of different biological activities but also served as model compounds for modern drug design [16, 19, 30]. The depsidone diploicin for example has inspired the development of clofazimine (Lamprene ${ }^{\circledR}$ ) and the group of riminophenazine antibiotics [21]. In regard to AGEs, Kumar et al. have recently reported the inhibition of their formation by crude extracts of Parmotrema species [15], however, to the best of the authors' knowledge, the present work is the first evaluation of that kind on single lichen constituents.

Results from these experiments are summarized in Table $\mathbf{1}$ and Fig. 1, which shows the structures of all active compounds. A complete compilation of the structures of all tested compounds is provided in the supplementary section (Fig. S1). 
Table 1 Lichen metabolites evaluated for their inhibitory effects on the formation of pentosidine-like AGEs and their radical scavenging capacity.

\begin{tabular}{|c|c|c|c|c|}
\hline Name & $\begin{array}{l}\mathrm{IC}_{50} \text { pentosidine } \\
\text { like AGEs } \mathrm{mM}\end{array}$ & $\begin{array}{l}\text { Fold inhibition compared to } \\
\text { aminoguanidine (FIA) }\end{array}$ & $\begin{array}{l}\text { DPPH expressed as } \mu \mathrm{mol} \\
\text { Trolox } ₫ / \mu \mathrm{mol} \text { sample }\end{array}$ & $\begin{array}{c}\text { Fold radical scavenging activity } \\
\text { of chlorogenic acid }\end{array}$ \\
\hline Acetylportentol $(\mathbf{1})^{(1,4)}$ & NA & NA & NA & NA \\
\hline Atranol $(\mathbf{2})^{(1,4)}$ & 0.15 & 12.7 & $0.11 \pm 10.21 \%$ & 0.10 \\
\hline Atranorin $(\mathbf{3})^{(1,4)}$ & NA & NA & NA & NA \\
\hline$\beta$-Collatolic acid $(\mathbf{4})^{(1,4)}$ & 0.20 & 9.5 & NA & NA \\
\hline Chloroatranol $(\mathbf{5})^{(1,4)}$ & 0.10 & 19.0 & $0.25 \pm 5.96 \%$ & 0.23 \\
\hline Chrysophanol $(\mathbf{6})^{(2,5)}$ & NA & NA & NA & NA \\
\hline Divaric acid $(7)^{(2,5)}$ & NA & NA & NA & NA \\
\hline Emodin $(\mathbf{8})^{(2,5)}$ & NA & NA & NA & NA \\
\hline Erythrin $(\mathbf{9})^{(1,4)}$ & NA & NA & NA & NA \\
\hline Evernic acid (10) & NA & NA & NA & NA \\
\hline $\begin{array}{l}\text { Fumarprotocetraric } \\
\text { acid }(\mathbf{1 1})^{(2,5)}\end{array}$ & 0.70 & 2.1 & NT & NT \\
\hline Gyrophoric acid* $(\mathbf{1 2})^{(3,6)}$ & NA & & NA & NA \\
\hline $\begin{array}{l}(+) \text {-Hemoventosin } \\
(\mathbf{1 3})^{(2,5)}\end{array}$ & NA & & NA & NA \\
\hline Leprapinic acid (14) ${ }^{(1,4)}$ & 0.08 & 25.3 & $0.52 \pm 3.45 \%$ & 0.49 \\
\hline $\begin{array}{l}\text { Lichesterinic } \\
\operatorname{acid}(\mathbf{1 5})^{(2,5)}\end{array}$ & NA & NA & NA & NA \\
\hline Lobaric acid (16) ${ }^{(1,4)}$ & 0.40 & 4.8 & NT & NT \\
\hline$m$-Scrobiculin* $\left(\mathbf{1 7}{ }^{(3,6)}\right.$ & NA & NA & $1.43 \pm 1.74 \%$ & 1.23 \\
\hline Methyl divarate* $(\mathbf{1 8})^{(3,6)}$ & NA & NA & NA & NA \\
\hline Methyl evernate (19) ${ }^{(2,5)}$ & NA & NA & NA & NA \\
\hline$\underset{(1,4)}{\text { Methyl } \beta \text { - orsellinate }(\mathbf{2 0})}$ & NA & NA & NA & NA \\
\hline Parietin $(\mathbf{2 1})^{(2,5)}$ & NA & NA & NT & NT \\
\hline Pannaric acid (22) ${ }^{(1,4)}$ & 0.06 & 31.7 & $0.67 \pm 1.73 \%$ & 0.63 \\
\hline
\end{tabular}




\begin{tabular}{|c|c|c|c|c|}
\hline Name & $\begin{array}{l}\mathrm{IC}_{50} \text { pentosidine } \\
\text { like AGEs } \mathrm{mM}\end{array}$ & $\begin{array}{l}\text { Fold inhibition compared to } \\
\text { aminoguanidine (FIA) }\end{array}$ & $\begin{array}{l}\text { DPPH expressed as } \mu \mathrm{mol} \\
\text { Trolox } \AA / \mu \mathrm{mol} \text { sample }\end{array}$ & $\begin{array}{c}\text { Fold radical scavenging activity } \\
\text { of chlorogenic acid }\end{array}$ \\
\hline Perlatolic acid $(\mathbf{2 3})^{(1,4)}$ & NA & NA & NA & NA \\
\hline Polyporic acid (24) & 0.30 & 6.3 & $0.28 \pm 6.21 \%$ & 0.26 \\
\hline $\begin{array}{l}\text { Protocetraric } \\
\text { acid }(\mathbf{2 5})^{(1,4)}\end{array}$ & 0.50 & 3.8 & NA & NA \\
\hline Rhizocarpic acid (26) ${ }^{(2,5)}$ & 0.40 & 3.6 & $0.33 \pm 8.75 \%$ & 0.25 \\
\hline$(+)$-Roccellic acid $(\mathbf{2 7})^{(1,4)}$ & NA & NA & NA & NA \\
\hline Scensidin $(\mathbf{2 8})^{(1,4)}$ & NA & NA & NA & NA \\
\hline $\begin{array}{l}\text { Secalonic } \\
\text { acid } D(\mathbf{2 9})\end{array}$ & 0.50 & 2.9 & NA & NA \\
\hline Solorinic acid $(\mathbf{3 0})^{(1,4)}$ & NA & NA & NA & NA \\
\hline Stictic acid* $(\mathbf{3 1})^{(3,6)}$ & 0.50 & 2.8 & NA & NA \\
\hline $\begin{array}{l}\text { Stictic acid } \\
\left(\text { open form) } *(\mathbf{3 2})^{(3,6)}\right.\end{array}$ & 0.35 & 4.0 & NA & NA \\
\hline Thamnolic acid (33) & 0.30 & & NA & NA \\
\hline $\begin{array}{l}\text { 2,3,4-Trihydroxy-6- } \\
\text { propylbenzoic acid methyl } \\
\text { ester* }(\mathbf{3 4})^{(3,6)^{*}}\end{array}$ & 0.40 & & $2.83 \pm 4.85 \%$ & 2.44 \\
\hline$(+)-$ Usnic Acid* $(35)^{(3,6)}$ & NA & NA & NA & NA \\
\hline Variolaric acid (36) ${ }^{(2,5)}$ & 0.05 & 29.0 & NA & NA \\
\hline Vulpinic acid (37) & 0.10 & 19.0 & $0.39 \pm 1.45 \%$ & 0.36 \\
\hline DU2 $(\mathbf{3 8})^{(1,4)}$ & NA & & NA & NA \\
\hline DU3 (39) $)^{(1,4)}$ & NA & & NA & NA \\
\hline DU4 (40) $)^{(1,4)}$ & 0.13 & 14.6 & NA & NA \\
\hline DU5 (41) $)^{(1,4)}$ & NA & & NA & NA \\
\hline PI-O (42) & NA & & NA & NA \\
\hline
\end{tabular}




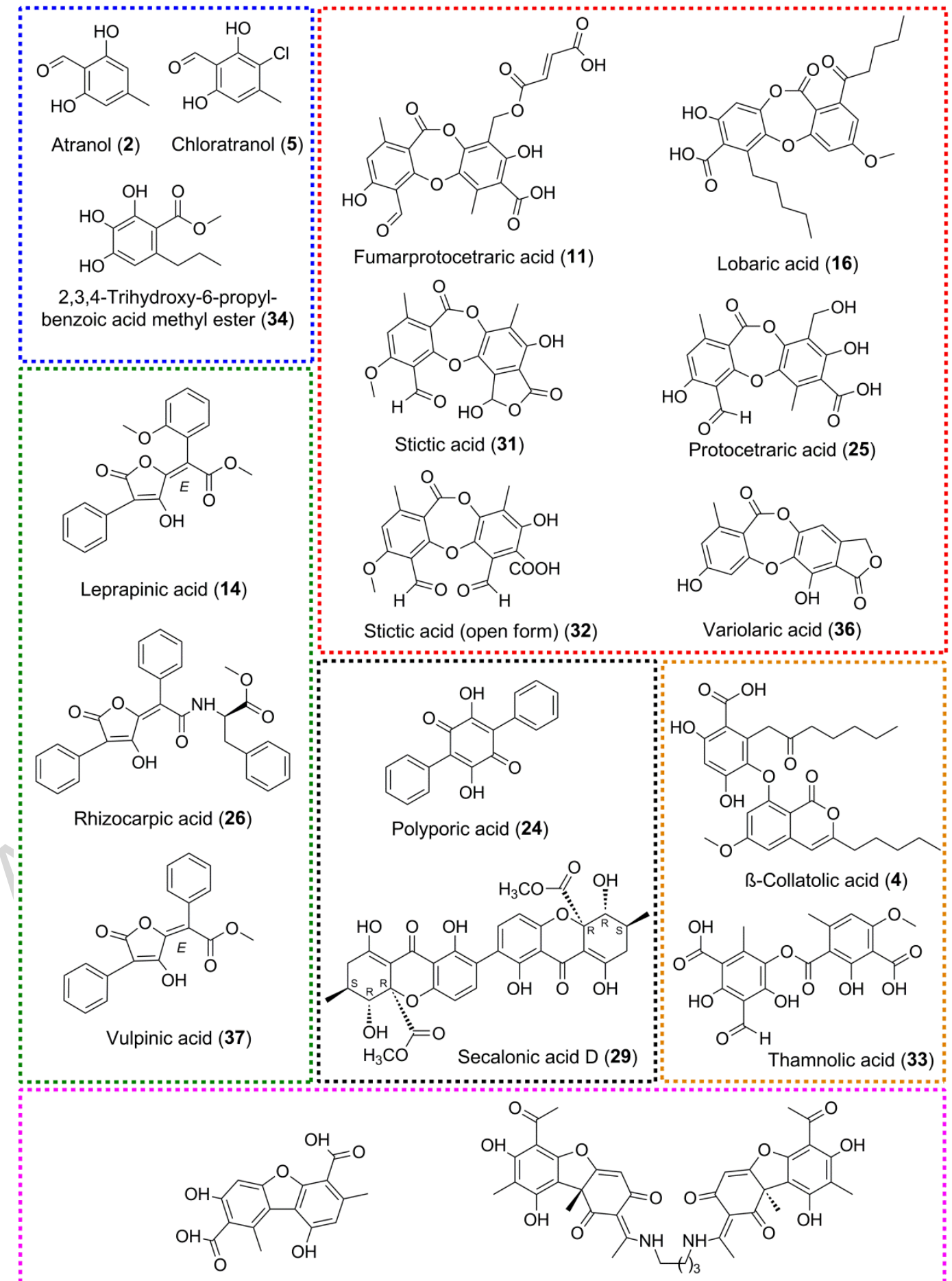


Fig.1. Secondary lichen metabolites exhibiting inhibitory effects on the formation of pentosidine-like AGEs. Compounds were grouped according to their chemical classification: blue monoaromatic phenolic compounds, red depsidones, green pulvinic acid derivatives, orange depsides and diphenylethers, black dihydroxy benzoquinone and xanthone derivatives, pink dibenzofurans and their dimers. 
Overall, seventeen natural and one semisynthetically modified compound exhibited notable inhibition of AGEs formation $\left[\mathrm{IC}_{50}<1.0\right.$ $\mathrm{mM}$, fold activity of aminoguanidine (FAA) $>2.0$ ]. Best activities $\left(\mathrm{IC}_{50}<0.1 \mathrm{mM}, \mathrm{FAA}>25\right)$ were observed for variolaric acid (36), pannaric acid (22) and leprapinic acid (14), which are in the range of previously tested flavonoids such as pinobanksin, pinobanksin-5methyl ether and pinobanksin-3-acetate as well as cinnamic acid derivatives 2-acetyl-1,3-dicoumaroylglycerol and prenyl caffeate $\left(\mathrm{IC}_{50}: 0.05-0.09 \mathrm{mM}\right)$ [31]. In terms of potential structure-activity relationships, it was interesting to observe that the entire group of tested depsidones (compounds 11, 16, 25, 31, 32 and 36) exhibited inhibitory effects (IC 50:0.05-0.70 mM, FAA 2.1-29.0). Noteworthy, most active 36 ( $\mathrm{IC}_{50}$ : $0.05 \mathrm{mM}$, FAA: 29.0), shows an additional dihydrofuran-2-one moiety, which is missing in the other depsidones. However, the general substitution pattern within this group is quite diverse thus preventing conclusive reasoning on structural key elements underlying the observed variation of activities.

Within the group of depsides and diphenylethers, compounds 4 and 33 ( $\mathrm{IC}_{50}: 0.20,0.30 \mathrm{mM}$, FAA: 9.5, 4.8) exhibited best inhibitory effects, while active monoaromatic phenols were identified as 2, 5 and 34 ( $\mathrm{IC}_{50}: 0.15,0.10,0.40 \mathrm{mM}$ and FAA: 12.7, 19.0, 3.5). For both groups, no clear structure activity relationship was observed. While compound $\mathbf{3 4}$ was active, $\mathbf{1 8}$ was not, and the only difference between the two structures is that $\mathbf{1 8}$ exhibits one phenolic group less than $\mathbf{3 4}$. On the other hand, structurally related $\mathbf{2}$, which shows the same number of phenolic functions as 18, was activity. The rest of active compounds was distributed among the following chemical groups: dihydroxy benzoquinone and xanthone derivatives 24, 29 ( $\mathrm{IC}_{50}: 0.30,0.50 \mathrm{mM}$, and FAA: 6.3, 2.9), pulvinic acid derivatives 14, 26 and 37 ( IC $_{50}: 0.08,0.40,0.10 \mathrm{mM}$, and FAA: 25.3, 19.0, 3.6) as well as the dibenzofuran 22 (IC $50: 0.06$ mM, FAA: 31.7 ) and its semisynthetically modified derivative 40 ( $\mathrm{IC}_{50}: 0.13 \mathrm{mM}$, FAA: 14.6). Particularly the group of synthetically modified derivatives of usnic acid (38-41) was quite interesting to study. It seems that the length of the connecting aliphatic diamine bridge has significant impact on the inhibition of AGEs formation. Solely compound $\mathbf{4 0}$ (bridge length five $\mathrm{CH}_{2}$ units) was active, while compounds with shorter or longer bridges did not show any inhibiting effects.

Contrary to some previous reports $[14,32]$, reductive and radical scavenging activity was not necessarily linked to the inhibition of AGEs formation. Solely eight out of the eighteen AGEs concurrently showed notable activity in the DPPH assay of at least $10 \%$ of chlorogenic acid (positive control). This inconsistency most likely indicates different modes of action for the inhibition of AGEs. Metal ions and reactive oxygen species (ROS) are key participants in the Maillard reaction [33], so the inhibiting effects of compounds like atranol (3), leprapinic acid (14) and pannaric acid (22) may be (in parts or in total) explained by their radical scavenging activities. Next to the latter also chelation is a reported mechanism for AGEs inhibition [33], and any compound shown in Fig 1 exhibits structural elements that may contribute to this effect. In this regard the complexation of human serum albumin (HSA) with cinnamic acid (CA) was reported to block one of the major glycating sites in HSA, thus preventing the formation of AGEs in the presence of glucose [34]. It is reasonable to assume that similar effects may occur under current experimental conditions. Nevertheless, it should 
be keep in mind that the current the experimental setting was not designed to allow conclusive reasoning on this specific mode of action and that in vivo AGEs formation involves additional and more complex mechanisms such as reported enzyme activities of superoxide dismutase and catalase [35].

For the time being, the present study has evaluated a limited number of compounds compared to the thousands of reported lichen metabolites. Besides, synergistic, activity-enhancing effects due to the presence of several active compounds as found in crude lichen extracts have not been studied but may have significant impact. Recently the crude acetonitrile extract of Parmotrema austrosinense has been reported to exhibit notable inhibitory effects on the formation of pentosidine-like AGEs [15]. The same study also reported atranorin (3), methyl-orcinol- $\beta$-carboxylate (20) and lecanoric acid as its major constituents. Considering the presently observed inactivity of $\mathbf{3}$ and 20, it is reasonable to assume that lecanoric acid may exhibit anti-AGEs effects. With all this in mind, present results provide a first, yet useful, indication of the promising potential of lichen metabolites as inhibitors of AGEs formation.

\subsection{Cytotoxic effects and their potential impact}

Beside various biological effects, some lichen compounds were also found to exhibit cytotoxicity [17, 19, 36], which may be a limiting factor for future therapeutic applications. Therefore a compilation of reported cytotoxicity for all lichen compounds that inhibited AGEs formation was added to the supplementary section of the manuscript (Table S3). In this regard $\beta$-Collatolic (4), leprapinic (14) and pannaric acid as well as (22) thamnolic acid (33) and 2,3,4-trihydroxy-6-propylbenzoic acid methyl ester (34) represent most interesting candidates for follow up studies. They all show notable anti-AGEs effects ( $\mathrm{IC}_{50}$ 0.06-0.5 mM) but no reported cytotoxicity. Further attention should also be given to atranol (2) and chloroatranol (5) as observed cytotoxicity (20-30\% of growth inhibition against PAM2.12 cells in an MTT assay at $0.6 \mathrm{mM}$ after $24 \mathrm{~h}$ ) is lower than their anti-AGEs effects (IC 50 : 0.10-015, mM) [37]. At this point, it is important to mention that a precise and meaningful evaluation of cytotoxicity of lichen metabolites requires an extended experimental protocol comprising different cell lines, different time points of evaluation and at least two mechanistically different bioassays. This is best exemplified by $\mathbf{3 1}$ and $\mathbf{3 2}$, which yielded contradicting results when being tested in a tetrazolium salt (WST-1) and a trypan blue (TrypB) cytotoxicity assay [19]. While both compounds showed strong cytotoxic against cancerous HL60 cells in the TrypB assay after 24h, results from the WST-1 assays seemingly indicated intense cell growth (160-180\% compared to the DMSO control) at that time. Eventually this discrepancy could be explained by a highly increased metabolic activity of cells that were still alive after 24h, thus masking cytotoxicity in the WST-1 assay. The effect lasted for up to 72 hours after incubation. Moreover, both 31 and 32 showed selective cytotoxicity against cancerous HL60 and HeLa cells while being inactive against non-cancerous Vero cells. In fact, the selectivity towards cancer cell is reported for many lichen compounds [19, 36, 38]. Consequently, potential follow up studies 
on biological material should include an adapted cytotoxicity protocol based on cell lines from to the target region of the desired antiAGEs effect (e.g. endothelial cells when analyzing the impact AGEs formation on atherosclerosis)

\subsection{Vasodilative effects of lichen metabolites}

Next to the formation of AGEs, hypertension is another major risk factor for many age and lifestyle related diseases. It was shown that the age-related progressive augmentation of blood pressure beyond levels of $115 / 75 \mathrm{~mm} \mathrm{Hg}$ is accompanied by an incremental rise in cardiovascular risk [39]. With this in mind, compounds 12, 17, 31, 32, 34, and 35 (which were available in sufficient quantities) were additionally tested on their impact on vascular reactivity. The latter is an accepted parameter for estimating the general state of the vascular system, which is progressively impaired in the course of diabetic long term complications [40]. Figure 2 shows the vasodilative effect of these six lichen metabolites evaluated on mesentery arteries of healthy male Wistar rats. For preserving best visibility, error bars (relative standard deviations) were not added the graph. This information is provided in Tab S1 and S2 (supplementary material). 


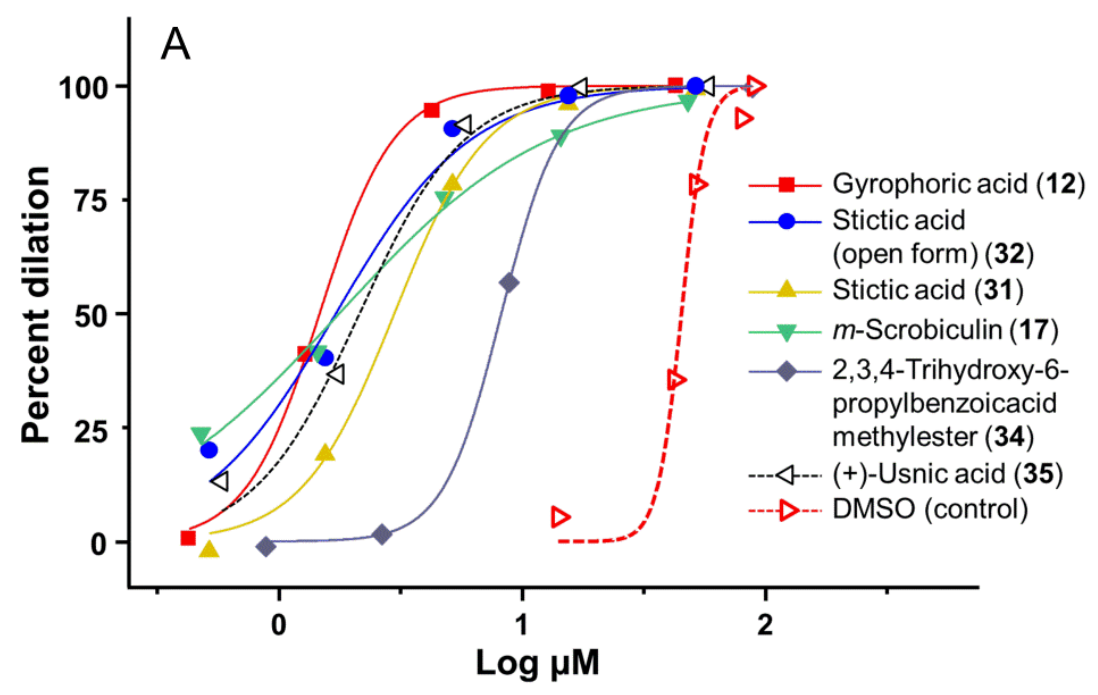

B
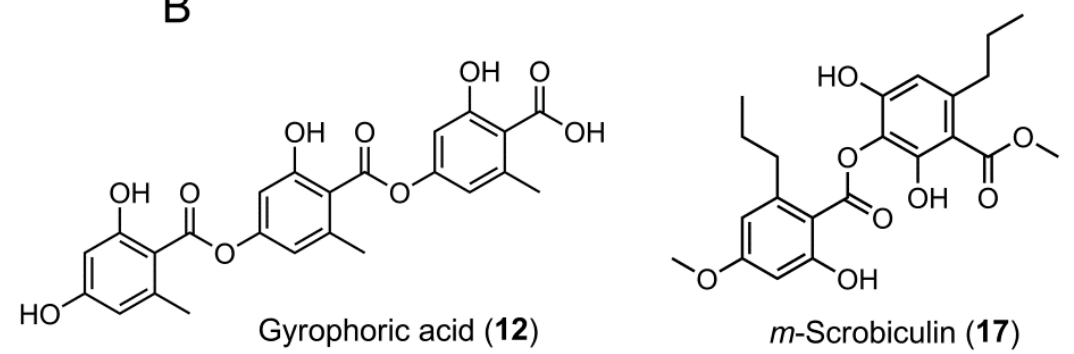

Fig. 2. A: Vasodilative effects of compounds $12,17,31,32,34$, and 35 on mesentery arteries pre-contracted with phenylephrine at a concentration of $2 \mu \mathrm{M}$. B: Structures of vasodilative compounds not shown in Fig $\mathbf{1}$.

All tested compounds exhibited notable vasodilative effects $\left(\mathrm{ED}_{50}: 1.5-3.0 \mu \mathrm{M}\right)$ compared to DMSO $\left(\mathrm{ED}_{50}: 11.6 \mu \mathrm{M}\right)$, which served as negative control. Neither radical scavenging activity nor the inhibition of AGEs seems to correlate with observed vasodilation. Vasodilative $12\left(\mathrm{ED}_{50}: 1.46 \mu \mathrm{M}\right)$ and $35\left(\mathrm{ED}_{50}: 2.13 \mu \mathrm{M}\right)$ did not show any further effects, while $31\left(\mathrm{ED}_{50}: 2.97 \mu \mathrm{M}\right)$ and $32\left(\mathrm{ED}_{50}\right.$ : $1.71 \mu \mathrm{M})$ inhibited the formation of AGEs, and $17\left(\mathrm{ED}_{50}: 1.77 \mu \mathrm{M}\right)$ exhibited additional reductive and radical scavenging activity. Interestingly compound 34, which notably inhibited AGEs' formation and which exhibited strong radical scavenging effects, was least active in the vasodilation assay ( $\left.\mathrm{ED}_{50}: 8.3 \mu \mathrm{M}\right)$. 
Hitherto, very little is known about the impact of lichen metabolites on the vascular system. Solely vulpinic acid (37) and leprapinic acid (14) were previously described as vasodilators [41, 42]. However, the presently identified vasodilative compounds belong to different chemical groups such as depsides $(\mathbf{1 2}, \mathbf{1 7})$, depsidones $(\mathbf{3 1}, \mathbf{3 2})$ and dibenzofurans $(\mathbf{3 5})$. Although not studied in the present work, it is reasonable to assume that further compounds from these groups may exhibit similar effects. 


\subsection{Inhibition of AGEs, AGEs' breakers and vasodilation as common therapeutic strategies}

As discussed earlier, the formation of AGEs severely impacts vessel functioning and is a major contributor to the development of atherosclerosis [6]. Moreover, arterial stiffening, an age-related effect but also an important long term complication of diabetes, is causally linked to the formation of AGEs on elastin and collagen [5]. Although there is no direct link between vasodilation and the inhibition of AGEs' formation, compounds exhibiting both effects may provide interesting leads for future drug design. Therapeutic interventions may limit or even prevent the formation of AGEs related arterial stiffening, while simultaneously lowering elevated levels of blood pressure by vasodilation. Moreover, some of the identified anti-AGEs compounds may potentially exhibit AGE crosslink breaking effects as observed for the thiazolium salt alagebrium. The latter was shown to partially reestablish vascular reactivity in type-2 diabetic rats [43], but did not show significant effects on arterial stiffness in healthy elderly humans [44]. Consequently, particularly the evaluation of presently identified anti-AGEs compounds in a diabetic vascular model represents an interesting subject for follow-up projects.

\section{Conclusion}

The present study has identified secondary lichen metabolites as potent inhibitors of AGEs' formation showing 2 to 32 fold higher activity than aminoguanidine. Some compounds additionally exhibited notable radical scavenging effects and vasodilation on precontracted mesentery arteries of healthy Wistar rats. For a better understanding of the underlying processes, active compounds should be tested in more complex biological in-vitro or in vivo systems targeting specific modes of action. This should also include a tailored cytotoxicity evaluation. In this respect, particularly the evaluation of AGE crosslink breaking activities may represent an interesting objective. Overall, the present work provides a first glimpse of future applications of secondary lichen metabolites and broadens the scope of their potential therapeutic utilization. 


\section{References}

[1] Jamwal S, Sharma S. Vascular endothelium dysfunction: a conservative target in metabolic disorders, Inflamm Res 67(5) (2018) 391-405.

[2] Bonnardel-Phu E, Wautier JL, Vicaut E. Advanced glycation end products are involved in microvascular permeability changes observed in microcirculation of diabetic rats in vivo, J Mal Vasc 25(2) (2000) 122-127.

[3] Batkulwar K, Godbole R, Banarjee R, Kassaar O, Williams RJ, Kulkarni MJ. Advanced Glycation End Products Modulate Amyloidogenic APP Processing and Tau Phosphorylation: A Mechanistic Link between Glycation and the Development of Alzheimer's Disease, ACS Chem Neurosci 9(5) (2018) 988-1000.

[4] Li J, Liu D, Sun L, Lu Y, Zhang Z. Advanced glycation end products and neurodegenerative diseases: mechanisms and perspective, J Neurol Sci 317(1-2) (2012) 1-5.

[5] Sells DR, Monnier VM. Molecular Basis of Arterial Stiffening: Role of Glycation Gerontology 58 (2012) $227-237$.

[6] Vasdes S, Gill V, Singal P. Role of Advanced Glycation End Products in Hypertension and Atherosclerosis: Therapeutic Implications, Cell Biochem Biophys 49 (2007) 48-63.

[7] Newman D.J., Cragg G.M., Natural Products as Sources of New Drugs over the 30 Years from 1981 to 2010 , J Nat Prod 75 (2012) 311-335.

[8] Dzib-Guerra W.D., Escalante-Erosa F., García-Sosa K., Derbré S., Blanchard P., Richomme P., Peña-Rodríguez L.M., AntiAdvanced Glycation End-product and Free Radical Scavenging Activity of Plants from the Yucatecan Flora, Pharmacognosy Res 8(4) (2016) 276-280.

[9] Costa E.V., Soares L.N., Pinheiro M.L.B., Maia B.H.L.N.S., Marques F.A., Barison A., Almeida JRGS, Sousa IL, Galaverna RS, Heerdt G, Morgon NH, Acho LDR, Lima ES, da Silva FMA, Koolen HHF. Guaianolide sesquiterpene lactones and aporphine alkaloids from the stem bark of Guatteria friesiana, Phytochem 145 (2018) 18-25.

[10] Spínola V, Castilho PC. Evaluation of Asteraceae herbal extracts in the management of diabetes and obesity. Contribution of caffeoylquinic acids on the inhibition of digestive enzymes activity and formation of advanced glycation end-products (in vitro), Phytochem 143 (2017) 29-35.

[11] Kato N, Kawabe S, Ganeko N, Yoshimura M, Amakura Y, Ito H. Polyphenols from flowers of Magnolia coco and their antiglycation effects, Biosci Biotechnol Biochem 81(7) (2017) 1285-1288.

[12] Li X, Liu GJ, Zhang W, Zhou YL, Ling TJ, Wan XC, Bao GH. Novel Flavoalkaloids from White Tea with Inhibitory Activity Against Formation of Advanced Glycation End Products, J Agric Food Chem 66(18) (2018) 4621-4629.

[13] Liu B, Li CP, Wang WQ, Song SG, Liu XM. Lignans Extracted from Eucommia Ulmoides Oliv. Protects Against AGEs-Induced Retinal Endothelial Cell Injury, Cell Physiol Biochem 39(5) (2016) 2044-2054.

[14] Harris CS, Beaulieu LP, Fraser MH, McIntyre KL, Owen PL, Martineau LC, Cuerrier A, Johns T, Haddad PS, Bennett SA, Arnason JT. Inhibition of advanced glycation end product formation by medicinal plant extracts correlates with phenolic metabolites and antioxidant activity, Planta Med 77(2) (2011) 196-204. 
[15] Kumar K, Siva B, Sarma VUM, Mohabe S, Reddy AM, Boustie J, Tiwari AK, Raoe NR, Babua KS. UPLC-MS/MS quantitative analysis and structural fragmentation study of five Parmotrema lichens from the Eastern Ghats, J Pharm Biomed Anal 156 (2018) 4557.

[16] Boustie J, Tomasi S, Grube M. Bioactive lichen metabolites: alpine habitats as an untapped source, Phytochemistry Reviews 10 (2011) 287-307.

[17] Backorova M, Backor M, Mikes J, Jendzelovsky R, Fedorocko P. Variable responses of different human cancer cells to the lichen compounds parietin, atranorin, usnic acid and gyrophoric acid, Toxicol in Vitro 25 (2011) 37-44.

[18] Ristic S, Rankovic B, Kosanic M, Stanojkovic T, Stamenkovic S, Vasiljevic P, Manojlovic I, Manojlovic N. Phytochemical study and antioxidant, antimicrobial and anticancer activities of Melanelia subaurifera and Melanelia fuliginosa lichens, J Food Sci Technol 53 (2016) 2804-17.

[19] Schinkovitz A, Kaur A, Urban E, Zehl M, Páchniková G, Wang Y, Kretschmer K, Slanino vá I, Pauli GF, Franzblau SG, Krupitza G, Bauer R, Kopp B. Cytotoxic Constituents from Lobaria scrobiculata and the Versatility of the Water Soluble Tetrazolium Salt-1 and Trypan Blue Bioassays for Their Identification, J Nat Prod 77 (2014) 1069-1073.

[20] Derbré S, Gatto J, Pelleray A, Coulon L, Séraphin D, Richomme P. Automating a 96-well microtiter plate assay for identification of AGEs inhibitors or inducers: application to the screening of a small natural compounds library, Anal Bioanal Chem 398(4) (2010) $1747-1758$.

[21] Reddy VM, O' Sullivan JF, Gangadharam PRJ. Antimycobacterial activities of riminophenazines J Antimicrob Chemother 43(5) (1999) 615-623.

[22] Grzegorczyk-Karolak I, Gołąb K, Gburek J, Wysokińska H, Matkowski A. Inhibition of Advanced Glycation End-Product Formation and Antioxidant Activity by Extracts and Polyphenols from Scutellaria alpina L. and S. altissima L., Molecules 21(6) (2016) 739.

[23] Le Pogam P, Boustie J, Richomme P, Denis A, Schinkovitz A, The inherent matrix properties of lichen metabolites in MALDITOF MS, Rapid Commun Mass Spectrom 31(23) (2017) 1993-2000.

[24] Le Pogam P, Schinkovitz A, Legouin B, Le Lamer AC, Boustie J, Richomme P. Matrix-Free UV-Laser Desorption Ionization Mass Spectrometry as a Versatile Approach for Accelerating Dereplication Studies on Lichens, Analytical Chemistry 87 (2015) $10421-10428$.

[25] Chollet-Krugler M, Tomasi S, Uriac P, Toupet L. Preparation and characterization of copper(II) and nickel(II) complexes of a new chiral salen ligand derived from (+)-usnic acid Dalton Trans 46 (2008) 6524-6526.

[26] Legouin B, Uriac P, Tomasi S, Toupet L, Bondon A, van de Weghe P. Novel Chiral Molecular tweezer from (+)-Usnic Acid, Org Lett 11(3) (2009) 745-748.

[27] Séro L, Sanguinet L, Blanchard P, Dang BT, Morel S, Richomme P, Séraphin D, Derbré S. Tuning a 96-well microtiter plate fluorescence-based assay to identify AGE inhibitors in crude plant extracts, Molecules 18(11) (2013) 14320-14339.

[28] Abdel-Lateff A, König GM, Fisch KM, Höller U, Jones PG, Wright AD. New antioxidant hydroquinone derivatives from the algicolous marine fungus Acremonium sp, J Nat Prod 65(11) (2002) 1605-1611. 
[29] Dugé de Bernonville T, Guyot S, Paulin JP, Gaucher M, Loufrani L, Henrion D, Derbré S, Guilet D, Richomme P, Dat JF, Brisset MN. Dihydrochalcones: Implication in resistance to oxidative stress and bioactivities against advanced glycation end-products and vasoconstriction, Phytochemistry 4 (2010) 443-452.

[30] Yamamoto Y., Hara K., Kawakami H., Komine M., Lichen Substances and Their Biological Activities, in: Dalip Kumar DU, Divakar PK, Shukula V, Bajpai R. (Eds.), Recent Advances in Lichenology, Springer India2015, pp. 181-200.

[31] Boisard S, Le Ray AM, Gatto J, Aumond MC, Blanchard P, Derbré S, Flurin C, Richomme P. Chemical composition, antioxidant and anti-AGEs activities of a French poplar type propolis, Journal of Agricultural and Food Chemistry 62(6) (2014) $1344-1351$.

[32] Perez Gutierrez RM, Flores Cotera LB, Gonzalez AM. Evaluation of the antioxidant and anti-glication effects of the hexane extract from Piper auritum leaves in vitro and beneficial activity on oxidative stress and Advanced Glycation End-Product-mediated renal injury in streptozotocin-treated diabetic rats, Molecules 17 (2012) 11897-11919.

[33] Nagai R, Murray DB, Metz TO, Baynes JW, Chelation: A Fundamental Mechanism of Action of AGE Inhibitors, AGE Breakers, and Other Inhibitors of Diabetes Complications, Diabetes 61(3) (2012) 549-559.

[34] Quais FA, Alam M, Naseem I, Ahmad I. Understanding the mechanism of non-enzymatic glycation inhibition by cinnamic acid: an in vitro interaction and molecular modelling study, RSC Adv 6 (2016) 65322-65337.

[35] Ghorbani A. Mechanisms of antidiabetic effects of flavonoid rutin, Biomed Pharmacother 96 (2017) 305-312.

[36] Brisdelli F, Perilli M, Sellitri D, Piovano M, Garbarino JA, Nicoletti M, Bozzi A, Amicosante G, Celenza G. Cytotoxic Activity and Antioxidant Capacity of Purified Lichen Metabolites: An In Vitro Study, Phytother Res 27 (2013) 431-437.

[37] Bonefeld CM, Nielsen M.M., Gimenéz-Arnau E., Lang M., Vennegaard M.T., Geisler C., Johansen JD, Lepoittevin JP. An immune response study of oakmoss absolute and its constituents atranol and chloroatranol, Contact Dermatitis 70(5) (2014) 282-290. [38] Brandão LF, Alcantara GB, Matos Mde F, Bogo D, Freitas Ddos S, Oyama NM, Honda NK. Cytotoxic evaluation of phenolic compounds from lichens against melanoma cells, Chem Pharm Bull 61(2) (2013) 176-183.

[39] Kokkinos P. Cardiorespiratory Fitness, Exercise, and Blood Pressure, Hypertension 64 (2014) 1160-1164.

[40] Naser A, McQuilkin GL, Akhtar MW, Hajsadeghi F, Kleis SJ, Hecht H, Naghavi M, Budoff M. Reproducibility and variability of digital thermal monitoring of vascular reactivity, Clin Physiol Funct Imaging 6 (2011) 422-428.

[41] Rao AVN. Prabhakar MC. Pharmacological actions of vulpinic acid, a lichen metabolite, Indian J Pharmacol 20(2-4) (1988) 143151.

[42] Rao AVN, Prabhakar MC. Pharmacological actions of leprapinic acid, a lichen metabolite, Fitoterapia 58(4) (1987) $221-228$.

[43] Freidja ML, Tarhouni K, Toutain B, Fassot C, Loufrani L, Henrion D. The AGE-Breaker ALT-711 Restores High Blood FlowDependent Remodeling in Mesenteric Resistance Arteries in a Rat Model of Type 2 Diabetes, Diabetes 61 (2012) $1562-1572$. [44] Oudegeest-Sander MH, Olde Rikkert MG, Smits P, Thijssen DH, Van Dijk AP, Levine BD, Hopman MT. The effect of an advanced glycation end-product crosslink breaker and exercise training on vascular function in older individuals: a randomized factorial design trial, Exp Gerontol 48(12) (2013) 1509-1517. 
The authors declare no conflict of interest

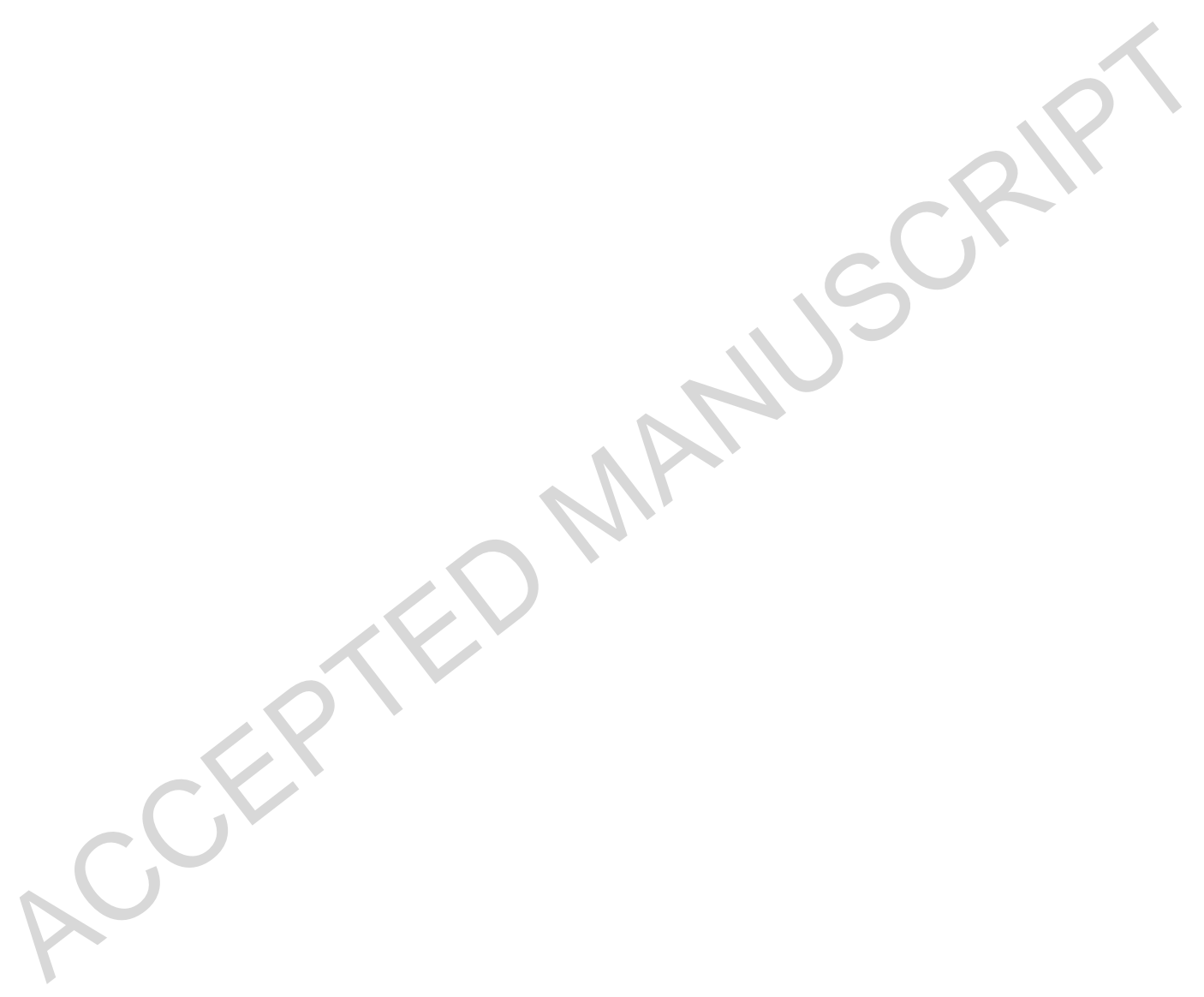


(c)

Atranol (2) Chloratranol (5)<smiles>CCCc1cc(O)c(O)c(O)c1C(=O)OC</smiles>

2,3,4-Trihydroxy-6-propylbenzoic acid methyl ester (34)<smiles>COC(=O)C(=C1OC(=O)C(c2ccccc2)=C1O)c1ccccc1OC</smiles>

Leprapinic acid (14)<smiles>COC(=O)C(Cc1ccccc1)NC(=O)C(=C1OC(=O)C(c2ccccc2)=C1O)c1ccccc1</smiles>

Rhizocarpic acid (26)

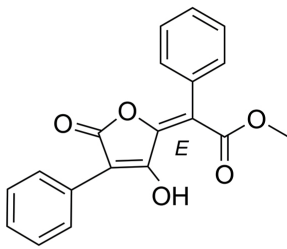

Vulpinic acid (37)

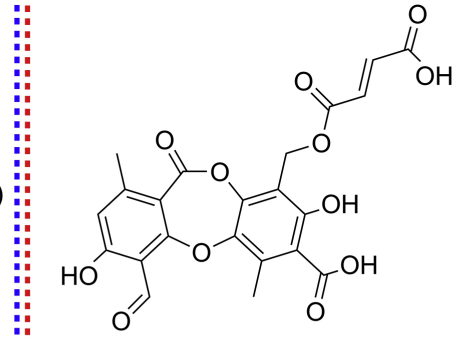

Fumarprotocetraric acid (11)<smiles>COc1cc(C)c2c(c1C=O)Oc1c(c(C)c(O)c3c1C(O)OC3=O)OC2=O</smiles>

Stictic acid (31)

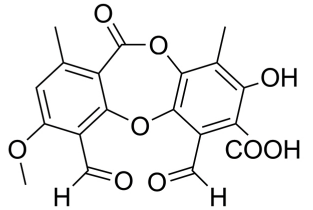

Stictic acid (open form) (32)<smiles>CCCCCc1c2c(cc(O)c1C(=O)O)OC(=O)c1c(cc(OC)cc1C(=O)CCC)O2</smiles>

Lobaric acid (16)<smiles>Cc1cc(O)c(C=O)c2c1C(=O)Oc1c(C)c(C(=O)O)c(O)c(CO)c1O2</smiles>

Protocetraric acid (25)<smiles>Cc1cc(O)cc2c1C(=O)Oc1cc3c(c(O)c1O2)C(=O)OC3</smiles>

Variolaric acid (36)<smiles>O=C1C(O)=C(c2ccccc2)C(=O)C(O)=C1c1ccccc1</smiles>

Polyporic acid (24)

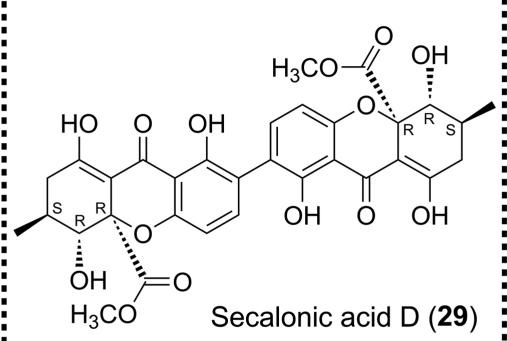

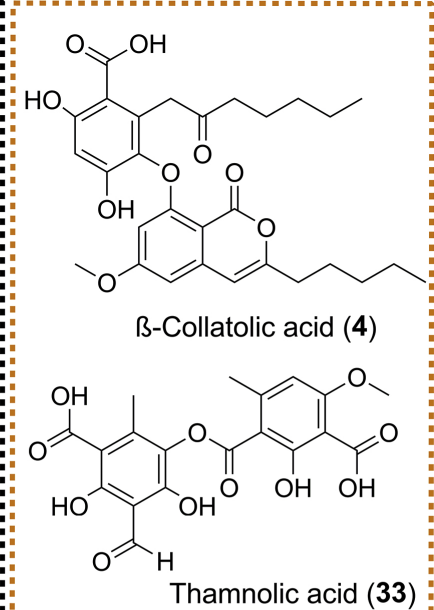

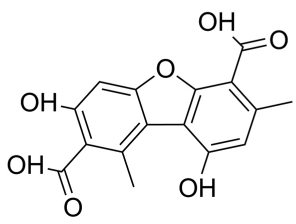

Pannaric acid (22)

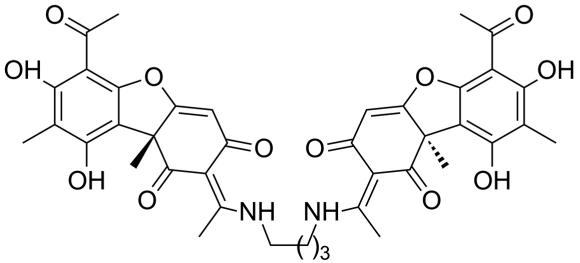

DU4 (40) 

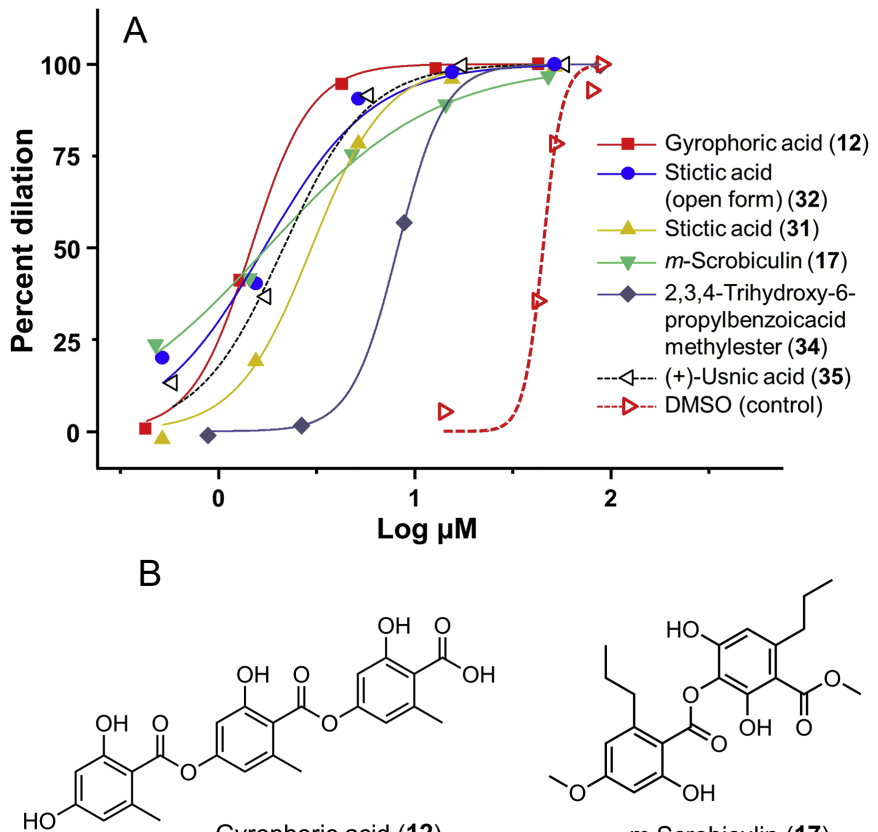

Gyrophoric acid (12)

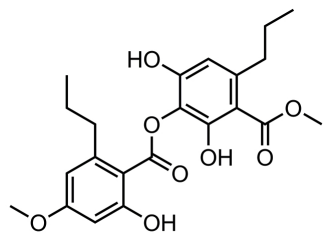

m-Scrobiculin (17)

Figure 2 